\title{
Experimental verification of a mathematical model for pelleted growth of Streptomyces coelicolor A3(2) in submerged batch culture
}

\author{
A. J. Tough and J. I. Prosser
}

Microbiology (1996), 142, 639-648

Owing to a printer's error, the right-hand axis labels of Fig. 5 parts (c) and (d) (p. 645) were printed incorrectly: they should read $10^{-3}$ and $10^{-4} \times$ Pellet number, respectively, instead of $10^{-1} \times$ Pellet number. The correct version is shown below.
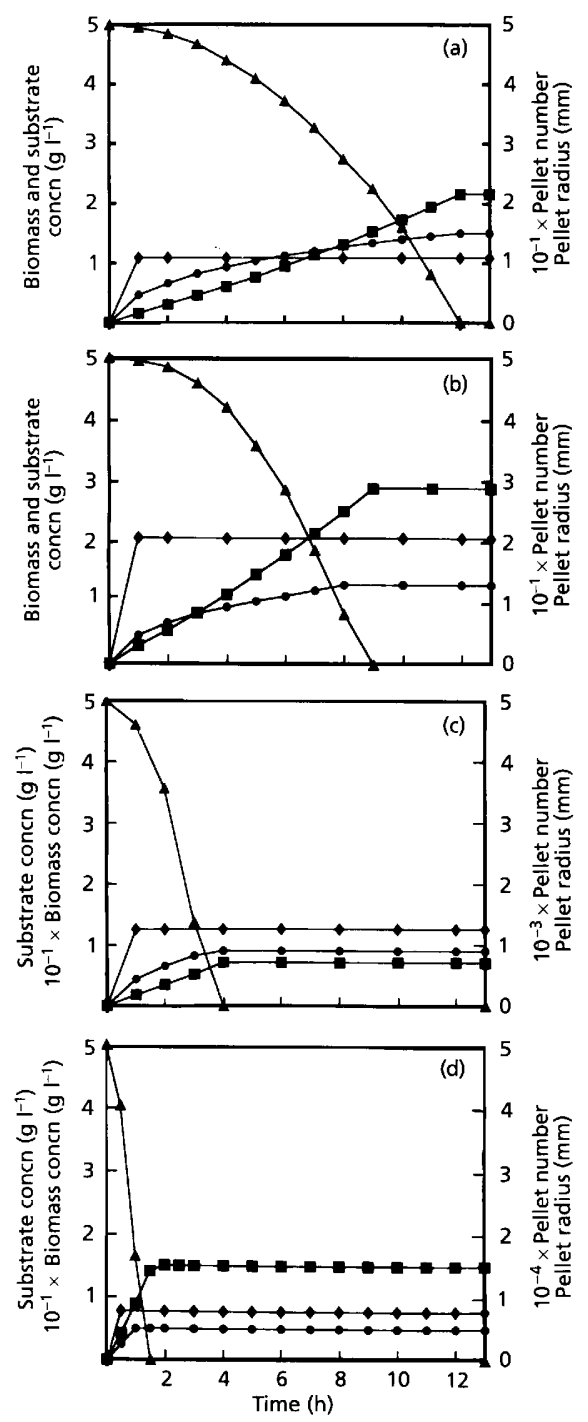

Fig. 5. Predicted changes in pellet radius (O), pellet concentration $(\bullet)$, biomass concentration $(\square)$ and substrate concentration $(\mathbf{\Delta})$ during batch growth of $S$. coelicolor $A 3(2)$ at agitation rates of (a) 250, (b) 500, (c) 750 and (d) 999 r.p.m. 